\title{
Immune reconstitution inflammatory syndrome associated with dermatophytoses in two HIV-1 positive patients in rural Tanzania: a case report
}

Herry Mapesi ${ }^{1,2,3^{*}}$ (D), Adrià Ramírez ${ }^{4}$, Marcel Tanner ${ }^{2,3}$, Christoph Hatz ${ }^{2,3}$, Emilio Letang ${ }^{1,2,3,5^{*}}$ and the KIULARCO Study Group

\begin{abstract}
Background: Immune reconstitution inflammatory syndrome associated with dermatophytoses (tinea-IRIS) may cause considerable morbidity. Yet, it has been scarcely reported and is rarely considered in the differential diagnosis of HIV associated cutaneous lesions in Africa. If identified, it responds well to antifungals combined with steroids. We present two cases of suspected tinea-immune reconstitution inflammatory syndrome from a large HIV clinic in rural Tanzania.

Cases presentation: A first case was a 33 years-old female newly diagnosed HIV patient with CD4 count of 4 cells/ $\mu \mathrm{L}(0 \%)$, normal complete blood count, liver and renal function tests was started on co-formulated tenofovir/ emtricitabine/efavirenz and prophylactic cotrimoxazole. Two weeks later she presented with exaggerated inflammatory hyperpigmented skin plaques with central desquamation, active borders and scratch lesions on the face, trunk and lower limbs. Tinea-IRIS was suspected and fluconazole (150 mg daily) and prednisolone (1 mg/Kg/ day tapered down after 1 week) were given. Her symptoms subsided completely after 8 weeks of treatment, and her next CD4 counts had increased to 134 cells/ $\mu \mathrm{L}(11 \%)$. The second case was a 35 years-old female newly diagnosed with HIV. She had $1 \mathrm{CD} 4$ cell/ $\mu \mathrm{L}(0 \%)$, haemoglobin $9.8 \mathrm{~g} / \mathrm{dl}$, and normal renal and liver function tests. Esophageal candidiasis and normocytic-normochromic anaemia were diagnosed. She received fluconazole, prophylactic cotrimoxazole and tenofovir/emtricitabine/efavirenz. Seven weeks later she presented with inflammatory skin plaques with elevated margins and central hyperpigmentation on the trunk, face and limbs in the frame of a good general recovery and increased CD4 counts (188 cells/ $\mu \mathrm{L}, 6 \%$ ). Tinea-IRIS was suspected and treated with griseofulvin $500 \mathrm{mg}$ daily and prednisolone $1 \mathrm{mg} / \mathrm{Kg}$ tapered down after 1 week, with total resolution of symptoms in 2 weeks.
\end{abstract}

Conclusion: The two cases had advanced immunosuppression and developed de-novo exaggerated manifestation of inflammatory lesions compatible with tinea corporis and tinea facies in temporal association with antiretroviral treatment initiation and good immunological response. This is compatible with unmasking tinea-IRIS, and reminds African clinicians about the importance of considering this entity in the differential diagnosis of patients with skin lesions developing after antiretroviral treatment initiation.

Keywords: HIV, Immune reconstitution inflammatory syndrome, Case report

\footnotetext{
*Correspondence: hmapesi@ihi.or.tz; emili.letang@unibas.ch

${ }^{1}$ Chronic Diseases Clinic of Ifakara, Ifakara Health Institute, P. O Box 53, Ifakara,

Tanzania

Full list of author information is available at the end of the article
} 


\section{Background}

Immune reconstitution inflammatory syndrome asociated with dermatophytoses (tinea-IRIS) may cause considerable morbidity given the high prevalence of fungal skin infections, especially in HIV/AIDS patients with late presentation. Despite having been reported to be associated with $52-78 \%$ of cutaneous associated IRIS [1], it has been scarcely reported and is rarely considered in the differential diagnosis of HIV-associated cutaneous lesions in Sub-Saharan Africa (SSA). If identified, it responds well to antifungals combined with steroids [2]. We present two photographically documented cases of suspected tinea-IRIS in HIV-individuals in rural Tanzania. The two patients developed the lesions two and 7 weeks respectively after starting antiretroviral treatment (ART). They were treated with fluconazole and griseofulvin respectively combined with oral prednisolone. The symptoms resolved after 8 and 2 weeks in both patients respectively.

\section{Case I presentation}

A 33 years-old Tanzanian woman presented to the HIV clinic suffering from skin itching for 3 months prior to the visit. She tested positive for HIV and she was enrolled in care. At the baseline physical examination she had pruritic papular eruptions (PPE) involving both upper and lower limbs. Other systems and the vital signs were unremarkable.

\section{Investigations}

Her baseline investigations showed CD4 count of 4 cells $/ \mu \mathrm{L}$ (0 \%), with normal complete blood count $(\mathrm{CBC})$, liver function test (LFT) and estimated glomerular filtration rate (eGFR). She had negative Cryptococcal plasma antigen (CRAG) and Venereal Disease Research Laboratory (VDRL) test. She also had negative Hepatitis $B$ surface antigen (HBsAg) and negative screening test for cervical cancer screening.

\section{Treatment}

She was started ART on day four after enrollment into care in our HIV-Clinic on co-formulated tenofovir disoproxil fumarate $300 \mathrm{mg} / \mathrm{em}$ tricitabine $200 \mathrm{mg}$ /efavirenz $600 \mathrm{mg}$ (TDF/FTC/EFV) with prophylactic cotrimoxazole, $960 \mathrm{mg}$ once daily. She was also prescribed symptomatic treatment for $\mathrm{PPE}$, receiving cetirizine $5 \mathrm{mg}$ once daily for 1 week.

\section{Outcome and follow-Up}

Two weeks after initiating ART she returned to the HIVclinic with an exaggerated inflammatory manifestation, including hyperpigmented skin plaques with central desquamation and active borders on the face, trunk and lower limbs. The lesions were itching and surrounded by scratchy lesions (Fig. 1). Tinea-IRIS was suspected and fluconazole (150 mg daily), prednisolone $(1 \mathrm{mg} / \mathrm{kg}$ for 1 weeks tapered down during the second week) and cetirizine $5 \mathrm{mg}$ once daily for 1 week were given. Her symptoms subsided after 8 weeks of antifungal treatment (Fig. 1). Her CD4 count after 2 months on ART increased to 134 cells $/ \mu \mathrm{L}(11 \%)$ (Table 1$)$.

\section{Case II presentation}

A 35 years-old newly HIV-diagnosed female presented to the HIV clinic complaining of generalized body itching associated with intermittent papular rashes involving both lower limbs, which had started 1 month prior to the visit. She also had difficult in swallowing and dry cough for 1 week. She reported experienced night sweats, weight loss and chest pain for the last months. On physical examination she had oral thrush, PPE involving both lower limbs and bronchial breath sounds on auscultation. Other systems explorations were normal.

\section{Investigations}

Her baseline CD4 count was of 1 cell/ $\mu \mathrm{L}$ (0 \%). Her CBC showed normocytic normochromic anemia (haemoglobin

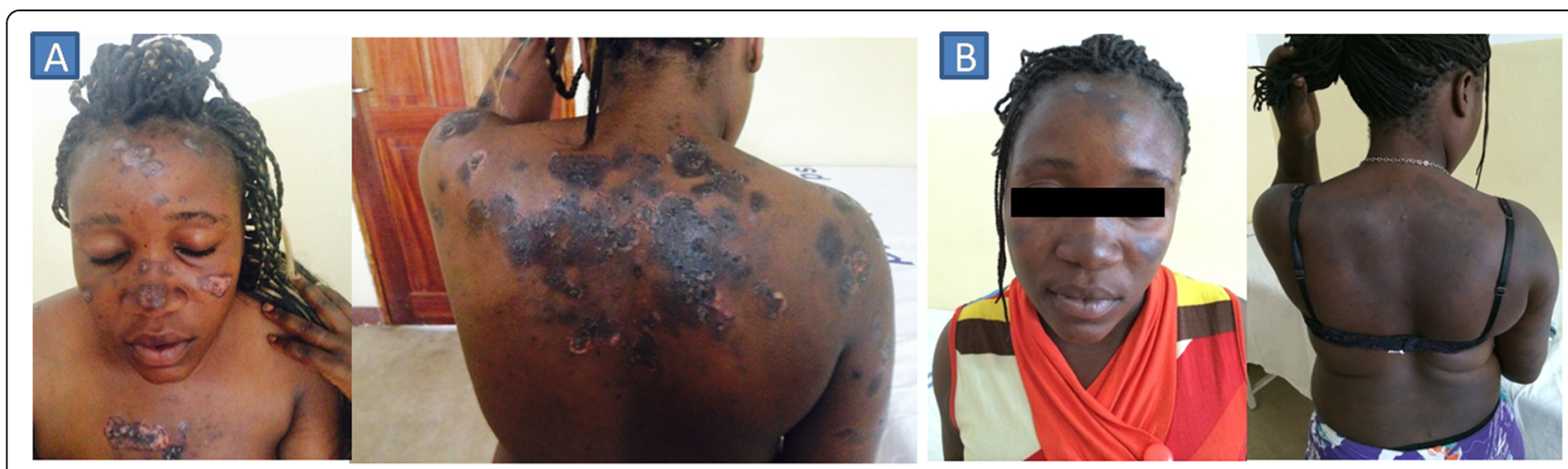

Fig. 1 Pictures of the case I before and after treatment. Picture a shows exaggerated inflammatory manifestation, including hyperpigmented skin plaques with central desquamation and active borders. The lesions were itching in nature surrounded by scratchy lesions on the face, trunk and lower limbs. Picture $\mathbf{b}$ shows improvement after 8 weeks treatment with fluconazole, prednisolone and cetirizine 
Table 1 Summary of clinical presentation, treatment and outcome of both patients

\begin{tabular}{|c|c|c|c|c|c|c|c|c|c|}
\hline Patient & $\begin{array}{l}\text { Initial } \\
\text { Diagnosis }\end{array}$ & $\begin{array}{l}\text { Baseline CD4 } \\
\text { Counts (cells/ } / \mu \mathrm{L})\end{array}$ & $\begin{array}{l}\text { Initial } \\
\text { Treatment }\end{array}$ & $\begin{array}{l}\text { Time to } \\
\text { IRIS (weeks) }\end{array}$ & Clinical Presentation & $\begin{array}{l}\text { Event CD4 } \\
\text { counts (cells/ } \mu \mathrm{L} \text { ) }\end{array}$ & $\begin{array}{l}\text { IRIS } \\
\text { Treatment }\end{array}$ & Outcome & $\begin{array}{l}\text { Time to } \\
\text { Response } \\
\text { (weeks) }\end{array}$ \\
\hline CASE I & $\begin{array}{l}\text { HIV WHO } \\
\text { stage II } \\
\text { PPE }\end{array}$ & 4 & $\begin{array}{l}\text { TDF/FTC/EFV } \\
\text { Cotrimoxazole } \\
\text { prophylaxis } \\
\text { Cetirizine }\end{array}$ & 2 & $\begin{array}{l}\text { Inflammatory lesions } \\
\text { on upper limbs, } \\
\text { face and trunk }\end{array}$ & $134^{a}$ & $\begin{array}{l}\text { Fluconazole } \\
\text { Prednisolone } \\
\text { Cetrizine }\end{array}$ & $\begin{array}{l}\text { Complete } \\
\text { response }\end{array}$ & 8 \\
\hline $\begin{array}{l}\text { CASE } \\
\|\end{array}$ & $\begin{array}{l}\text { HIV WHO } \\
\text { Stage IV } \\
\text { CAP } \\
\text { Esophageal } \\
\text { candidiasis }\end{array}$ & 1 & $\begin{array}{l}\text { TDF/FTC/EFV } \\
\text { Amoxicillin } \\
\text { Fluconazole } \\
\text { Cotrimoxazole } \\
\text { prophylaxis }\end{array}$ & 7 & $\begin{array}{l}\text { Inflammatory lesions } \\
\text { on upper limbs, } \\
\text { face and trunk }\end{array}$ & 188 & $\begin{array}{l}\text { Griseofulvin, } \\
\text { Prednisolone } \\
\text { Cetrizine }\end{array}$ & $\begin{array}{l}\text { Complete } \\
\text { response }\end{array}$ & 2 \\
\hline
\end{tabular}

CAP community acquired pneumonia, IRIS, immune reconstitution inflammatory syndrome, PPE papular pruritic eruption, TDF/FTC/EFV tenofovirdisoproxilfumarate / emtricitabine / efavirenz

${ }^{\mathrm{a}} \mathrm{CD} 4$ measured 6 weeks after the event

$9.8 \mathrm{~g} / \mathrm{dl}, \mathrm{MCV} 86$ femtoliter, MCH 28 picograms/cell) with an otherwise unremarkable CBC and normal LFT and eGFR. She had negative CRAG, VDRL, HBsAg and cervical cancer screening. Her chest radiograph showed alveolointerstitial opacities involving the left lower lobe and a diagnosis of community acquired pneumonia (CAP) was reached. Sputum smears were negative for Acid Fast Bacilli and Xpert MTB/RIF on sputum was negative as well.

\section{Treatment}

She received fluconazole $150 \mathrm{mg}$ once daily for 21 days for oropharyngeal and suspected esophageal candidiasis, amoxicillin $1 \mathrm{~g}$ three times daily during week one for CAP, prophylaxis with cotrimoxazole $960 \mathrm{mg}$ once daily and $400 \mathrm{mg}$ of ferric ammonium citrate / $3 \mathrm{mg}$ of folic acid daily for 1 month for anemia. She started ART 3 days later with TDF/FTC/EFV.

\section{Outcome and follow-up}

Seven weeks after ART initiation she started to experience skin rashes in both upper limbs, which rapidly involved the neck, trunk and the face (Fig. 2). The lesions clinically progressed to inflammatory skin plaques with elevated margins and central hyperpigmentation on the trunk, face and limbs in the frame of a good general recovery and increased CD4 count and percentage (188 cells/ $\mu \mathrm{L}-6 \%$ ). Tinea-IRIS was suspected and treated with griseofulvin $500 \mathrm{mg}$ once daily with prednisolone $1 \mathrm{mg} / \mathrm{kg}$ for 1 week tapered down during the second week and cetirizine $5 \mathrm{mg}$ once daily for 1 week. At the end of the second week of antifungal and steroid treatment, there was total resolution of the lesions (Fig. 2) (Table 1).

\section{Discussion}

The occurrence of PPE in adult African patients has been observed as highly predictive of HIV infection [3] and has been correlated with low CD4+ cell count $(<200$ cells/l). Differential diagnosis of PPE includes tinea, a fungal infection which involves the keratinized epidermis, nails, and hair caused by common opportunistic pathogens associated with HIV.

No comprehensive studies on dermatophyte infections have been conducted on HIV-individuals in low-income countries (LIC), where more than $90 \%$ of the global HIVinfected population resides. Prevalence of tinea infestation among people living with HIV (PLHIV) is likely to be high and to occur in all HIV-infected patients at one point of their lives [4]. Three types of dermatophytes account for the majority of infections: Epidermophyton, Trichophyton, and Microsporum. The most common dermatophytes affecting PLHIV includes Trichophyton rubrum, which is known to be the most prevalent, followed by Trichophyton mentagrophytes, Trichophyton tonsurans, Candida albicans, and Epidermophyton floccosum [5]. The infection in PLHIV has been associated with the degree of immunosuppression, being more frequent with low CD4 count like in our two patients. The clinical presentation range from being asymptomatic to disseminated disease affecting all four extremities.

Tinea, also known as ring worm, is the term representing a variety of skin mycoses and its diagnosis could be confirmed by potassium hydroxide $(\mathrm{KOH})$ examination of scrapings from material taken from the active border of the lesions. This is a very simple laboratory examination which should be made widely available in resource limited settings. A fungal culture on Sabouraud's medium can also be used to confirm the diagnosis, although it is slower. Although the etiological diagnosis relies on microbiological techniques, in rural settings of LIC diagnosis is mostly based on clinical judgment.

The availability of ART in SSA has significantly improved the quality of life for PLHIV. However, despite the fact that ART usually causes viral load suppression and restores patient's immunity, in some patients the restored immune response is immunopathological and causes the immune reconstitution inflammatory syndrome (IRIS) [6]. IRIS occurs when immunity is restored especially in the 


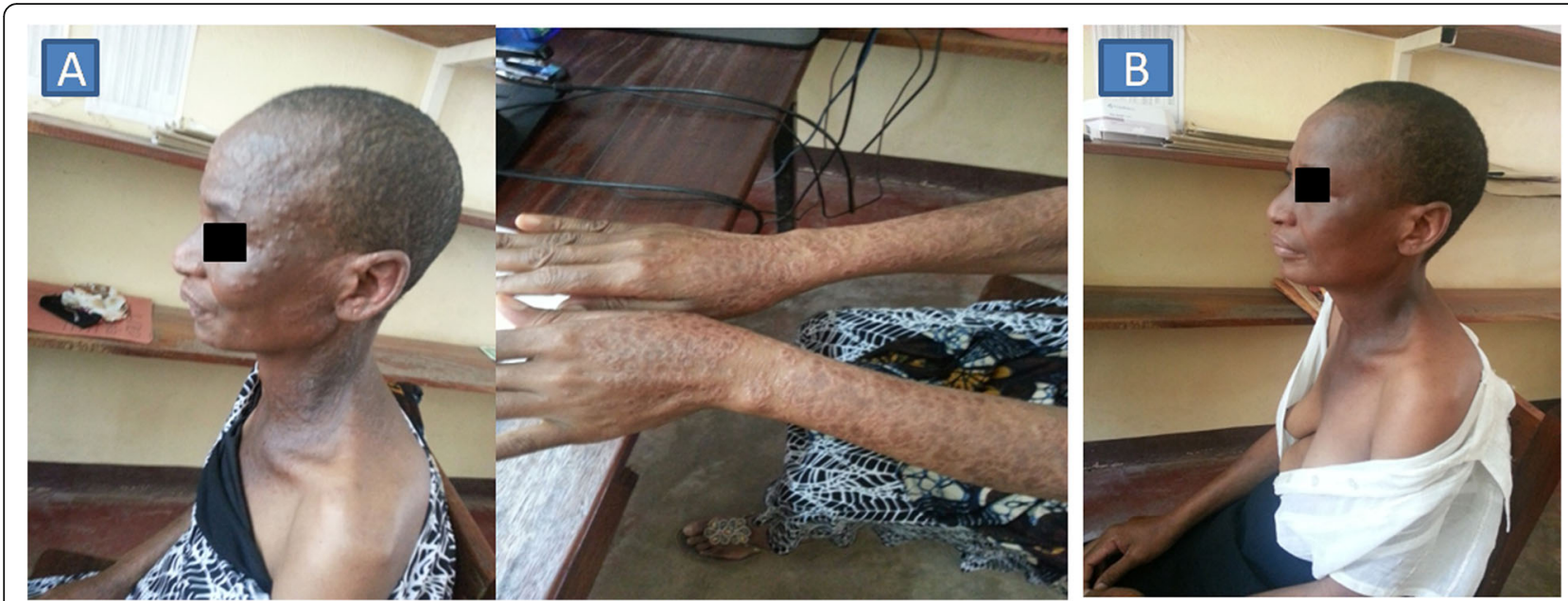

Fig. 2 Pictures of the case II before and after treatment. Picture a shows inflammatory skin plaques with elevated margins and central hyperpigmentation on the trunk, face and limbs 7 weeks after ART initiation. Picture $\mathbf{b}$ shows improvement after 2 weeks treatment with griseofulvin, prednisolone and cetirizine

first months of effective ART. In a prospective cohort study conducted among HIV patients in South Africa, $10.4 \%$ of patients initiating ART developed IRIS [7]. Mucocutaneous manifestations of IRIS have been poorly documented. A study conducted in Mozambique showed $26.5 \%$ of patients developed IRIS after a median time of 62 days from ART initiation with $53 \%$ of them having mucocutaneous manifestations. Tinea accounted for $47 \%$ of all mucocutaneous IRIS cases [8]. In another study conducted in Brazil, 10-25\% of unselected patients starting ART developed IRIS with $52-78 \%$ of these patients presenting with cutaneous features $[1,9]$. Tinea-IRIS lesions can be visible on patient's skin, and despite not being associated with mortality can cause a decrease in the quality of life [10]. Moreover, it requires a high index of suspicion to be treated.

In this report, we present two HIV infected patients whom we suspected to develop tinea-IRIS after starting ART. The first case developed tinea-IRIS 2 weeks after starting ART and was successfully treated with fluconazole and prednisolone. The second case presented with suspected tinea-IRIS 7 weeks after starting ART. With the evidence of increase in resistance to fluconazole after a prolonged exposure and the fact that she was treated for esophageal candidiasis with fluconazole for 3 weeks, she was treated with oral griseofulvin and prednisolone and her symptoms subsided completely after 2 weeks of treatment. Although highly suggestive of IRIS due to the temporal association with ART initiation and the concomitant immune reconstitution, de novo dermatophyte infection cannot be ruled out in this case [11]. We treated both patients with two locally available antifungals which have shown to be effective against tinea infection and can be combined with steroids [2].

\section{Conclusion}

To our knowledge these are the first two cases with tineaIRIS to be reported in Tanzania. The two cases presented had advanced immunosuppression and developed denovo exaggerated inflammatory lesions compatible with tinea corporis and facies in temporal association with ART initiation and good immunological response. This is compatible with unmasking tinea-IRIS, and reminds African clinicians about the importance of considering this entity in the differential diagnosis of patients with skin lesions developing after ART initiation, as fungal skin infestation is likely to be widely prevalent. Close follow-up is warranted in late presenters to timely identify and treat IRIS. In LIC like Tanzania where there are 4,993 estimated cases of serious fungal infections per 100,000 person/year, clinical judgment, appropriate microbiological tests and laboratory trained technicians are vital [12]. Additionally, since treatment with readily available in LIC antifungals such as fluconazole and griseofulvin combined with predinisolone have been proved to be effective, early diagnosis and treatment is paramount to reduce the associated morbidity, as shown by these two cases.

\footnotetext{
Abbreviations

CAP: Community acquired pneumonia; CBC: Compete blood count; CRAG: Cryptococcal plasma antigen; eGFR: Estimated glomerular filtration rate; HBsAg: Hepatitis B surface antigen; HIV: Human immunodeficiency virus; IRIS: Immune reconstitution inflammatory syndrome; $\mathrm{KOH}$ : Potassium hydroxide; LFT: Liver function test; LIC: Low-income countries; MCH: Mean corpuscular hemoglobin; MCV: Mean corpuscular volume; PLHIV: People living with HIV; PPE: Pruritic papular eruptions; SSA: Sub-Saharan Africa; TDF/FTC/EFV: tenofovir/ emtricitabine/efavirenz; Tinea-IRIS: Tinea-immune reconstitution inflammatory syndrome; VDRL: Venereal disease research laboratory
}

\section{Acknowledgements}

We would like to acknowledge the contribution made by Nora Tan from Stanford University in reviewing the manuscript. We would like to acknowledge the contributions from all members of Kilombero and Ulanga Antiretroviral 
Cohort (KIULARCO) study group. The KIULARCO and the Chronic Diseases Clinic of Ifakara (CDCl) receive financial support from the Government of the Canton of Basel, Switzerland, the Swiss Tropical and Public Health Institute, the Ifakara Health Institute, the Government of Tanzania, and USAID through TUNAJALI-Deloitte. The members of the KIULARCO Study Group are: Aschola Asantiel, Manuel Battegay, AdolphinaChale, Diana Faini, Ingrid Felger, Gideon Francis, Hansjakob Furrer, Anna Gamell, Tracy Glass, Christoph Hatz, Specioza Hwaya, Bryson Kasuga, Namvua Kimera, Yassin Kisunga, Thomas Klimkait, Emilio Letang, Antonia Luhombero, Lameck B Luwanda, Herry Mapesi, Leticia Mbwile, Mengi Mkulila, Julius Mkumbo, Margareth Mkusa, Dorcus K Mnzava, Germana Mossad, Dolores Mpundunga, Athumani Mtandanguo, Kim D Mwamelo, Selerine Myeya, Sanula Nahota, Regina Ndaki, Agatha Ngulukila, Alex John Ntamatungiro, Leila Samson, George Sikalengo, Marcel Tanner, Fiona Vanobberghen, Aneth V Kalinjuma and Maja Weisser.

\section{Funding}

No additional funds was required for this case report.

\section{Availability of data and materials}

Data can be found in the electronic databases of KIULARCO.

\section{Authors contribution}

$\mathrm{HM}$ and EL were involved in the clinical management of both patients. HM, AR and EL wrote the manuscript. MT, $\mathrm{CH}$, and EL contributed to draft the manuscript. All authors read and approved the final version of the manuscript.

\section{Authors' information}

$\mathrm{HM}$ is a medical doctor working at the chronic diseases clinic of Ifakara (CDCI) and currently a pursuing a Masters of Epidemiology at Swiss Tropical and Public Health Institute and University of Basel, Basel, Switzerland. AR is a resident of internal medicine at University Hospital Son Espases, Palma de Mallorca, Spain. MT is the former director of the Swiss Tropical and Public Health Institute of Basel, Switzerland. CH is the Chief medical officer and head of the Medical Services and Diagnostic at the Swiss Tropical and Public Health Institute of Basel, Switzerland and Head of Social-and Preventive Medicine Institute at the University Zürich. EL is an internal medicine specialist and the Head of the Chronic Diseases Clinic of Ifakara.

\section{Competing interest}

The authors declare that they have no competing interests.

\section{Ethics and consent to participate}

Both patients had given their written informed consent to participate in the Kilombero and Ulanga Antiretroviral Cohort (KIULARCO). The KIULARCO study received ethical approval from the Ifakara Health Institute Institutional Review Board, the National Institute for Medical Research of Tanzania, the Tanzanian Commission of Science and Technology, and the Ethics Committee of the University and State of Basel.

\section{Consent for publication}

Written informed consent was obtained from both patients for publication of this case report and the accompanying images. A copy of the written consent is available for review by the Editor of this journal.

\section{Author details}

'Chronic Diseases Clinic of Ifakara, Ifakara Health Institute, P. O Box 53, Ifakara, Tanzania. ${ }^{2}$ University of Basel, Basel, Switzerland. ${ }^{3}$ Chronic Diseases Clinic of Ifakara, Swiss Tropical \& Public Health Institute (Swiss TPH), Ifakara Health Institute (IHI), Ifakara branch, P.O. Box 53, Ifakara, Tanzania. ${ }^{4}$ University Hospital Son Espases, Palma de Mallorca, Spain. ${ }^{5}$ ISGLOBAL, Barcelona Ctr. Int. Health Res. (CRESIB), Hospital Clínic-Universitat de Barcelona, Barcelona, Spain

\section{Received: 13 February 2016 Accepted: 9 September 2016}

Published online: 20 September 2016

\section{References}

1. Osei-Sekyere B, Karstaedt AS. Immune reconstitution inflammatory syndrome involving the skin. Clin Exp Dermatol. 2010;35(5):477-81.
2. Ansari S, Hedayati MT, Zomorodian K, Pakshir K, Badali H, Rafiei A, et al. Molecular characterization and in vitro antifungal susceptibility of 316 clinical isolates of dermatophytes in Iran. Mycopathologia. 2015;14.

3. Colebunders R, Mann JM, Francis H, Bila K, Izaley L, Kakonde N, et al. Generalized papular pruritic eruption in African patients with human immunodeficiency virus infection. AIDS Lond Engl. 1987;1(2):117-21.

4. Coldiron BM, Bergstresser PR. Prevalence and clinical spectrum of skin disease in patients infected with human immunodeficiency virus. Arch Dermatol. 1989;125(3):357-61.

5. Rodwell GEJ, Bayles CL, Towersey L, Aly R. The prevalence of dermatophyte infection in patients infected with human immunodeficiency virus. Int J Dermatol. 2008;47(4):339-43.

6. French MA, Price P, Stone SF. Immune restoration disease after antiretroviral therapy. AIDS Lond Engl. 2004;18(12):1615-27.

7. Murdoch DM, Venter WDF, Feldman C, Van Rie A. Incidence and risk factors for the immune reconstitution inflammatory syndrome in HIV patients in South Africa: a prospective study. AIDS Lond Engl. 2008;22(5):601-10.

8. Letang E, Miro JM, Nhampossa T, Ayala E, Gascon J, Menendez C, et al. Incidence and Predictors of Immune Reconstitution Inflammatory Syndrome in a Rural Area of Mozambique. PLoS ONE [Internet]. 2011 Feb 28 [cited 2014 Sep 8];6(2). Available from: http://www.ncbi.nlm.nih.gov/pmc/articles/ PMC3046140/

9. da Silva BCM, Paula CR, Auler ME, Ruiz da S L, Dos Santos Jl, Yoshioka MCN, et al. Dermatophytosis and immunovirological status of HIV-infected and AIDS patients from Sao Paulo city, Brazil. Mycoses. 2014;57(6):371-6.

10. Singh F, Rudikoff D. HIV-associated pruritus: etiology and management. Am J Clin Dermatol. 2003;4(3):177-88.

11. Hryncewicz-Gwóźdź A, Kalinowska K, Plomer-Niezgoda E, Bielecki J, Jagielski T. Increase in resistance to fluconazole and itraconazole in Trichophyton rubrum clinical isolates by sequential passages in vitro under drug pressure. Mycopathologia. 2013;176(1-2):49-55.

12. Faini D, Maokola W, Furrer H, Hatz C, Battegay M, Tanner M, et al. Burden of serious fungal infections in Tanzania. Mycoses. 2015:58 Suppl 5:70-9.

\section{Submit your next manuscript to BioMed Central and we will help you at every step:}

- We accept pre-submission inquiries

- Our selector tool helps you to find the most relevant journal

- We provide round the clock customer support

- Convenient online submission

- Thorough peer review

- Inclusion in PubMed and all major indexing services

- Maximum visibility for your research

Submit your manuscript at www.biomedcentral.com/submit
Biomed Central 